\title{
Original Article (short paper) \\ A program of physical activity improves gait impairment in people with Alzheimer's disease
}

\author{
Diego Orcioli-Silva ${ }^{1}$, Fabio Augusto Barbieri², Lucas Simieli², Paulo Cezar Rocha dos Santos ${ }^{1,3}$, Victor Spiandor \\ Beretta $^{1}$, Flávia Gomes de Melo Coelho ${ }^{4}$, Larissa Pires de Andrade ${ }^{5}$, Lilian Teresa Bucken Gobbi ${ }^{1}$ \\ ${ }^{1}$ Universidade Estadual Paulista, UNESP, Posture and Gait Studies Laboratory (LEPLO), Rio Claro, SP, Bra- \\ zil; ' ${ }^{2}$ Universidade Estadual Paulista, UNESP, School of Science, Movement Research Laboratory (MOVI-LAB), \\ Bauru, SP, Brazil; ${ }^{3}$ University of Groningen, University Medical Center Groningen, Center for Human Mo- \\ vement Sciences, The Netherlands; ${ }^{4}$ Universidade Federal do Triângulo Mineiro, UFTM, Uberaba, MG, Bra- \\ zil; ${ }^{5}$ Universidade Federal de São Carlos, UFSCar, Department of Physiotherapy, São Carlos, SP, Brazil.
}

\begin{abstract}
Aim: This study aimed to identify the effects of aging and Alzheimer's disease (AD) on gait parameters after a four-month period and to investigate the effects of a four-month program of physical activity, with emphasis on the cognitive components of gait during single and dual task, in people with AD. Methods: Twenty-three people

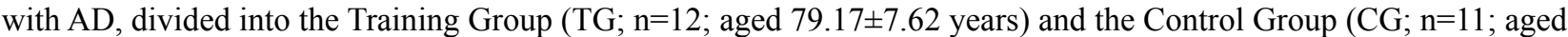
$77.00 \pm 5.57$ years), and eleven healthy older adults (Healthy Group - HG; aged 75.82 \pm 4.83 years) were included in this study. TG participated in a physical activity program for four months. The CG and HG were instructed not to participate in any kind of regular physical activity in this period. The physical activity program includes motor activities and cognitive tasks simultaneously. The participants attended a 1-h session three times a week. The kinematic parameters of gait were analyzed under two conditions, before and after a physical activity program: single and dual task. Deltas for all dependent variables between pre and post training were calculated. The deltas were compared using two-way ANOVAs with group (TG x CG and CG x HG) and task (single x dual task) as factors, with repeated measures for task. Results: After the training period, the TG improved stride length, duration, velocity and cadence compared to the CG. Conclusion: Physical activity with emphasis on cognitive components promotes better reallocation of attention while walking in people with $\mathrm{AD}$, improving attentional focus on the gait and thus resulting in a safer locomotive pattern.
\end{abstract}

Keywords: physical activity; cognitive components; gait impairments; dual task; Alzheimer's disease.

\section{Introduction}

Changes in gait are associated with normal aging and may be aggravated in the people with Alzheimer's disease (AD) ${ }^{1}$. Gait adjustments in patients with $\mathrm{AD}$ have been explained by frontal lobe dysfunctions, especially in the motor cortex ${ }^{2}$, and by an intense decrease in executive functions ${ }^{3}$. Typically, people with AD have a shorter stride length, reduced cadence and gait speed, and a higher double support phase of gait compared to neurologically healthy older adults ${ }^{1,4,5}$. Deficits in gait are even greater when people with $\mathrm{AD}$ perform a task simultaneously with gait (dual task $)^{5-7}$, increasing the temporal gait parameters (single and double support phase and stride duration) and reducing the gait speed and cadence, compared to gait without a cognitive task (single task). Thus, people with AD are more prone to falls when compared to healthy older adults ${ }^{8}$, with a fall rate of 4 to 5 times per year $^{9}$. As a way to prevent the effects of $\mathrm{AD}$ on locomotion in this population, the practice of regular physical activity is recommended.

The reviewed studies suggest that physical activity can benefit brain function, prevent cognitive decline $e^{10,11}$ and reduce the incidence of $\mathrm{AD}^{10}$. Previous studies have indicated that a physical exercise program improves mobility of people with $\mathrm{AD}^{12-14}$. However, the interventions in these studies were focused only on the components of physical capacity (i.e., muscle strength, endurance, balance, etc.), without emphasizing the cognitive component that is important to improve gait ${ }^{15}$.
Training of the cognitive component improves the frontal cognitive functions, stride length and performance during dual task. Studies have developed an exercise program with cognitive load $^{14,16,17}$. These studies showed that cognitive exercise, besides improving the frontal cognitive functions, such as abstraction, organization, motor sequencing, behavioral self-control and attention, also improves stride length and performance during dual task in people with AD. Despite the important results found in the previous study, no studies have investigated the behavior of gait temporal parameters after cognitive exercise. Gait temporal parameters are important due to their relationship with good gait performance and falls ${ }^{18}$. Furthermore, the absence of a control group of healthy older adults does not differentiate which effects are related to AD and which are inherent to aging. The inclusion of this group in the experimental design allows us to clearly identify the decline in the gait performance of the people with $\mathrm{AD}$ and the effects of physical activity against this decline.

Therefore, the aims of this study were to identify the effects of aging and $\mathrm{AD}$ on the gait parameters after a four-month period and to investigate the effects of a four-month program of physical activity, with emphasis on cognitive components on gait, during single and dual task in people with AD. After four months of inactivity, we expected a slight decline in gait performance in people with $\mathrm{AD}$ and maintenance of the healthy older adults, who did not participate in the physical activity program. In addition, as cognitive load training caused improvements in the frontal cognitive function of people with $\mathrm{AD}$, we expected that 
the spatial and temporal parameters of gait improve during single and dual tasks in the participants of the physical activity program.

\section{Methods}

\section{Participants}

The study included 30 older adults, who were diagnosed with AD according to the Diagnostic and Statistical Manual of Mental Disorders (DSM-IV-TR) and 15 healthy older adults. All participants were community-dwelling citizens in Rio Claro, Sao Paulo, Brazil. The AD patients were divided into Training Group (TG) and Control Group (CG). The healthy older adults constituted the Healthy Group (HG). The TG participated in a multimodal exercise intervention. The CG and HG were instructed not to participate in any kind of regular or systematic physical activity for a period of four months.

Out of the 45 participants initially evaluated, 11 were excluded because of musculoskeletal, orthopedic, visual or auditory impairment, or other neurological disorders that affected walking. Individuals with stage three or higher AD, participants from TG that did not complete a $70 \%$ minimum attendance rate in the exercise sessions, and participants from CG or HG that started to attend a physical activity program, were also excluded (Figure 1). The study sample was composed of twelve AD patients in the TG, eleven in the $\mathrm{CG}$ and eleven healthy older adults in the HG (Table 1). All 23 AD patients maintained the routine pharmacological treatment determined by their doctor.

Figure 1. Flowchart of training and assessment of study participants.

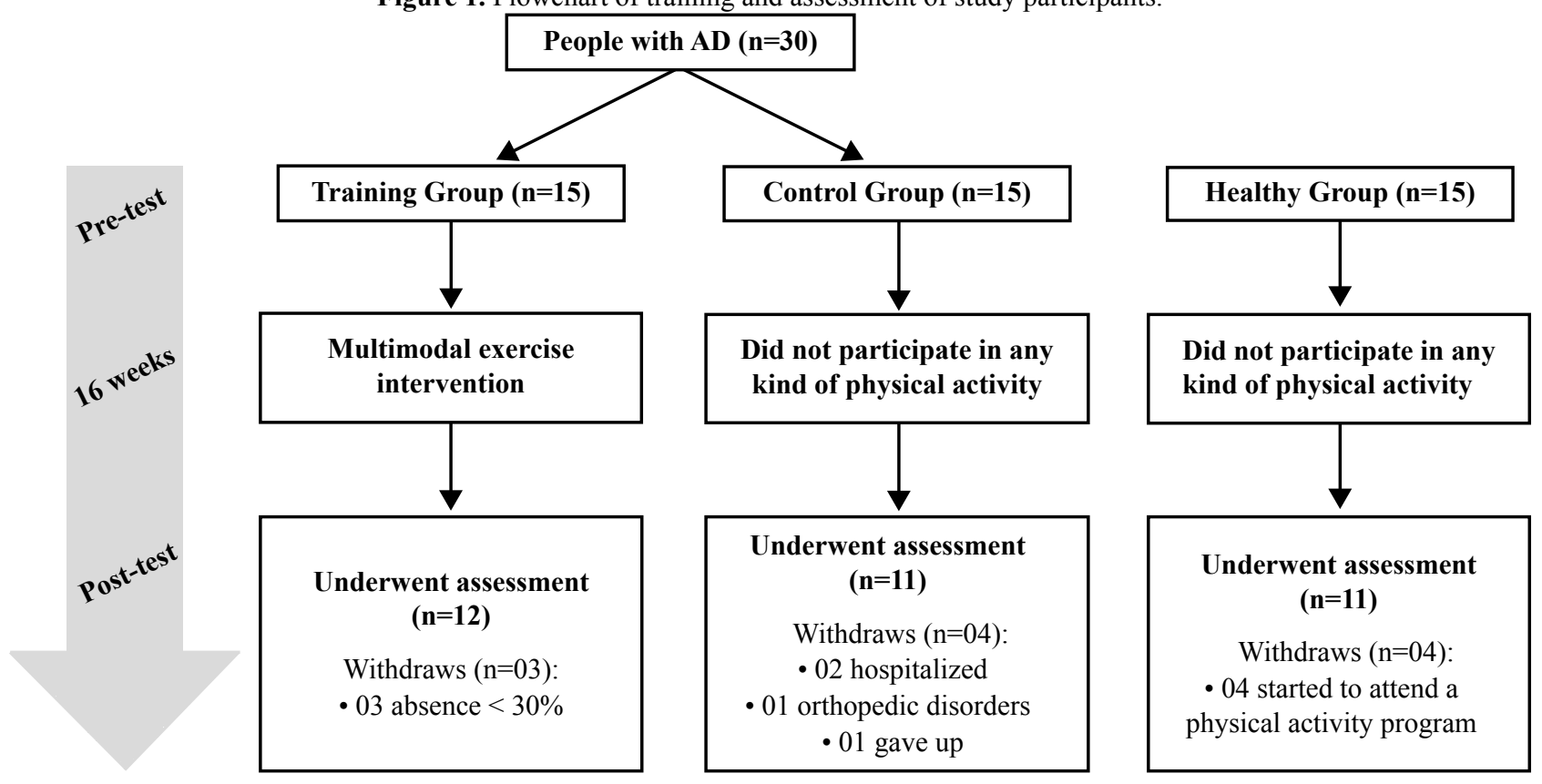

\section{Methodological procedures}

The protocol applied in this study was approved by the local Research Ethics Committee (Protocol no. 3083). A structured interview was performed to obtain clinical and sociodemographic data, such as age, sex, educational level and medication. All patients initially underwent evaluation with a geriatric psychiatrist. During this evaluation, the diagnosis of AD was confirmed clinically. AD patients were evaluated using the Clinical Dementia Rating scale (CDR) to measure the stage of disease. Cognitive functioning of the all individuals was assessed using the Mini-Mental State Examination $(\mathrm{MMSE})^{19}$, the Clock-Drawing Test $(\mathrm{CDT})^{20}$, the Frontal Assessment Battery (FAB) ${ }^{21}$ and Symbol Search-Subtest of the Wechsler Adult Intelligence Scale-III (symbol).

All tests were administered by a trained, blinded evaluator. Data collection was performed at the beginning of the program and 4 months after the initial assessment. The experimental task consisted of performing the single and dual task. The instruction given to the participants was to walk over an $8 \mathrm{~m}$ pathway at a self-selected velocity. For the dual task trial, the participants were also instructed to countdown aloud from 20 to 1 whilst walking $^{5,7}$. Each participant performed five trials for each condition. The trials were randomized for each participant. The number of errors in the cognitive task was recorded.

For the assessment of kinematic parameters of gait, we used a digital camera (model GR-DVL 9800; JVC, Manaus, Brazil), with 60 samples/s, positioned in the right sagittal plane. The digitization of images was performed using a video capture card (Pinnacle, model DV Studio, version 1.05.307) coupled to a microcomputer. The photogrammetric procedures (tracking, measuring and two-dimensional reconstruction) were performed using the Digital Video Software for Windows (version6.3; Laboratório de Instrumentação em Biomecânica - Unicamp; Campinas, Sao Paulo, Brazil). The calibration of two-dimensional space recorded by the camera was carried out with a plumb wire with known measurements. Four reflective markers were fixed on the lateral face of the calcaneus and head of the 5 th metatarsal of the right lower limb and the medial face of the calcaneus and head of the 1st metatarsal of the left lower limb. The data were filtered using a second-order digital Butterworth 
filter with a cut-off frequency of $4 \mathrm{~Hz}$ using Matlab software (version 7.0; Matworks, Natick, MA, USA). A routine written in Matlab language was developed for the analysis of kinematic variables of gait. The right stride in the middle of the pathway was analyzed and the length, duration, speed, cadence and percentage of the double support phase were measured.

\section{Intervention}

The physical activity program was structured to promote greater frontal cognitive stimulation, in other words, a motor activity and a frontal cognitive task were performed together (dual task). The intervention was carried out in the Program of Cognitive and Functional Kinesiotherapy for Seniors with Alzheimer's disease (PRO-CDA) - a 1-h session three times a week on nonconsecutive days over a period of 16 weeks.

The multimodal exercise intervention consisted of several modalities, such as strength/resistance training, aerobic capacity, flexibility, balance, agility, and, concomitantly, cognitive activities requiring focused attention, planned organization of the answers, abstraction, motor sequencing, judgment, behavioral self-control and mental flexibility. For example, participants were instructed to carry out a motor task (bouncing ball, walking, exercise with weights) and, at the same time, carry out a cognitive task, such as generating words according to semantic criteria (such as animal names, names of fruits, personal names, names of flowers and figures) or reacting to sensory stimuli (whistle a song) and verbal commands. During the intervention, the complexity of the tasks increased. The cognitive overload was defined according to previous experience, developed in the PRO-CDA, and was carried out by increasing the level of difficulty of the task. In the exercises with weights, the loads were increased and the types of exercises were changed. The intensity of the intervention on aerobic capacity was maintained between $65 \%$ and $75 \%$ of maximum heart rate, at a level appropriate for their age and considered e moderate. Heart rate was recorded at the beginning of, during, and at the end of each session. Blood pressure was also measured during the intervention, both procedures being adopted as safety measures ${ }^{17}$.

\section{Statistical analysis}

The analysis with $G^{*}$ Power software showed that a sample size of moderate magnitude of at least 27 individuals are needed in order to have $80 \%$ probability of detecting differences of $20 \%$ between the three groups for the primary outcome with a type I error of 0.05 ( 0.85 actual power $)^{14}$. Kinematics parameters were analyzed in SPSS 22.0 for Windows. The amount of change from pre- to post-test was calculated from the delta of all dependent variables using the equation below:

\section{DELTA $=$ variable $(\mathrm{X})$ after training - variable $(\mathrm{X})$ before training}

Positive delta results show an increase in the value of the variable after the training period, and negative delta results show a reduction in the value of the variable after the training period.

The Shapiro-Wilk and Levene tests were used to verify the normal distribution of data and homogeneity of variances, respectively. Independent-samples test $\mathrm{T}$ was used to compare the clinical, walk variables and errors in the countdown between the groups before the intervention (TG x CG and CG x HG). The deltas were compared using two-way ANOVA with group and task (single $\mathrm{x}$ dual task) as factors, with repeated measures for task, to verify the effects of aging ( $\mathrm{CG} \mathrm{x} \mathrm{HG)} \mathrm{and} \mathrm{the} \mathrm{effects}$ of the intervention ( $\mathrm{TG} \times \mathrm{CG}$ ). In addition, the number of errors in the countdown while walking was analyzed by independentsamples test $\mathrm{T}$. When univariate analyses were significant, Tukey post hoc tests were used to indicate the differences between the conditions. The significance level was 0.05 . The partial $\eta^{2}$ statistic provided estimates of the effect sizes.

\section{Results}

The TG and CG were similar with respect to clinical, cognitive and anthropometric characteristics. The CG and HG showed similar anthropometric characteristics, however, HG presented a higher score in the cognitive functions (MMSE; $\mathrm{t}_{20}=-11.29$, $\mathrm{p}<0.001$ ), executive functions (CDT; $\mathrm{t}_{20}=-4.24, \mathrm{p}<0.001$ ), frontal cognitive functions $\left(\mathrm{FAB} ; \mathrm{t}_{20}=-7.28, \mathrm{p}<0.001\right)$ and attention $\left(\right.$ Symbol; $\left.\mathrm{t}_{20}=-8.76, \mathrm{p}<0.001\right)($ Table 1$)$.

Table 1: Clinical, cognitive and anthropometric characteristics of the participants. The final two columns show the comparison between groups ( $<<0.05$ ).

\begin{tabular}{|c|c|c|c|c|c|}
\hline & \multirow{2}{*}{$\begin{array}{l}\text { Training Group } \\
\text { (3 m; 9 w) }\end{array}$} & \multirow{2}{*}{$\begin{array}{l}\text { Control Group } \\
\text { (1 m; } 10 \mathrm{w})\end{array}$} & \multirow{2}{*}{$\begin{array}{l}\text { Healthy Group } \\
\text { (2 m; 9 w) }\end{array}$} & \multicolumn{2}{|c|}{ Comparison between groups } \\
\hline & & & & TG x CG & CG $\times$ HG \\
\hline Age (years) & $79.17 \pm 7.62$ & $77.00 \pm 5.57$ & $75.82 \pm 4.83$ & ns & ns \\
\hline Weight (kg) & $66.66 \pm 11.05$ & $58.82 \pm 6.70$ & $67.17 \pm 12.51$ & ns & ns \\
\hline Height (cm) & $155.65 \pm 8.72$ & $152.52 \pm 3.33$ & $156.39 \pm 7.20$ & ns & ns \\
\hline Schooling (years) & $6.17 \pm 3.93$ & $3.91 \pm 1.45$ & $5.86 \pm 3.49$ & ns & ns \\
\hline Clinical Dementia Rating (points) & $1.5 \pm 0.52$ & $1.73 \pm 0.47$ & -------- & ns & -------- \\
\hline Frontal Assessment Battery (points) & $9.25 \pm 3.52$ & $8.27 \pm 3.41$ & $16.18 \pm 1.17$ & ns & $\mathbf{C G}<\mathbf{H G}$ \\
\hline Clock Drawing Test (points) & $6.25 \pm 2.80$ & $5.82 \pm 2.40$ & $8.90 \pm 0.30$ & ns & $\mathbf{C G}<\mathbf{H G}$ \\
\hline $\begin{array}{c}\text { Mini-Mental State Examination } \\
\text { (points) }\end{array}$ & $20.00 \pm 2.97$ & $18.64 \pm 4.43$ & $28.09 \pm 1.22$ & ns & $\mathbf{C G}<\mathbf{H G}$ \\
\hline Symbol Search (points) & $5.64 \pm 3.11$ & $6.18 \pm 2.36$ & $17.45 \pm 5.23$ & ns & $\mathbf{C G}<\mathbf{H G}$ \\
\hline Attendance to the sessions (\%) & $88.19 \pm 7.28$ & -------- & -------- & -------- & -------- \\
\hline
\end{tabular}


In the pre-test period, T-test indicated that the $\mathrm{HG}$ missed fewer numbers in the countdown in relation to the $\mathrm{CG}\left(\mathrm{t}_{20}=\right.$ $3.73, \mathrm{p}=0.001)$. In addition, $\mathrm{HG}$ presented greater stride length $\left(\mathrm{t}_{20}=-5.92, \mathrm{p}<0.001\right)$ and stride velocity $\left(\mathrm{t}_{20}=-5.15, \mathrm{p}<0.001\right)$ compared to the CG. There were no differences between the TG and CG in the countdown and gait parameters (Table 2).

After the training period, the ANOVA showed no difference in the effect of task and interaction for both comparison, TG x CG and CG x HG. However, in the comparison between
TG and CG, the ANOVA revealed a main effect of group in the stride length $\left(F_{1,21}=11.207, p=0.003\right.$, partial $\left.\eta^{2}=0.348\right)$, stride duration $\left(\mathrm{F}_{1,21}=5.431, \mathrm{p}=0.03\right.$, partial $\left.\eta^{2}=0.205\right)$, stride velocity $\left(\mathrm{F}_{1,21}=18.796, \mathrm{p}<0.001\right.$, partial $\left.\eta^{2}=0.472\right)$ and cadence $\left(\mathrm{F}_{1,21}=8.641, \mathrm{p}=0.008\right.$, partial $\left.\eta^{2}=0.292\right)$. The post hoc test showed that the TG improved the stride length, duration, velocity, and cadence compared to the CG. The T-test showed no difference for intervention or aging/DA effect in the countdown delta score between groups (TG x CG and CG x HG) (Table 2).

Table 2. Spatiotemporal parameters of gait by group, task, moment and delta. The final two columns show the main effects of group ( $<<0.05$ ).

\begin{tabular}{|c|c|c|c|c|c|c|c|c|c|}
\hline \multirow{2}{*}{\multicolumn{2}{|c|}{ Gait parameters }} & \multicolumn{2}{|c|}{ Training Group } & \multicolumn{2}{|c|}{ Control Group } & \multicolumn{2}{|c|}{ Healthy Group } & \multicolumn{2}{|c|}{ Effects of Group } \\
\hline & & Single task & Dual task & Single task & Dual task & Single task & Dual task & TG $\times$ CG & CG $\times$ HG \\
\hline \multirow{3}{*}{$\begin{array}{c}\text { Stride } \\
\text { length }(\mathrm{cm})\end{array}$} & Pre & $89.65 \pm 9.24$ & $85.24 \pm 13.76$ & $83.22 \pm 18.35$ & $78.40 \pm 16.12$ & $125.85 \pm 15.27$ & $124.99 \pm 17.01$ & \multirow{3}{*}{$\mathrm{TG}>\mathrm{CG}$} & \multirow{3}{*}{$\mathrm{ns}$} \\
\hline & Post & $96.94 \pm 12.12$ & $92.67 \pm 14.87$ & $82.26 \pm 18.25$ & $77.42 \pm 15.36$ & $126.19 \pm 16.10$ & $125.20 \pm 18.56$ & & \\
\hline & Delta & $7.29 \pm 6.85$ & $7.44 \pm 8.76$ & $-0.97 \pm 2.84$ & $-0.98 \pm 6.57$ & $0.33 \pm 5.08$ & $0.22 \pm 6.63$ & & \\
\hline \multirow{3}{*}{$\begin{array}{c}\text { Stride } \\
\text { duration (s) }\end{array}$} & Pre & $1.23 \pm 0.11$ & $1.83 \pm 0.70$ & $1.19 \pm 0.14$ & $1.73 \pm 0.36$ & $1.11 \pm 0.08$ & $1.23 \pm 0.11$ & \multirow{3}{*}{$\mathrm{TG}<\mathrm{CG}$} & \multirow{3}{*}{ ns } \\
\hline & Post & $1.17 \pm 0.13$ & $1.60 \pm 0.43$ & $1.21 \pm 0.17$ & $1.70 \pm 0.36$ & $1.11 \pm 0.10$ & $1.25 \pm 0.14$ & & \\
\hline & Delta & $-0.06 \pm 0.08$ & $-0.23 \pm 0.32$ & $0.02 \pm 0.07$ & $-0.03 \pm 0.20$ & $0.00 \pm 0.06$ & $0.02 \pm 0.14$ & & \\
\hline \multirow{3}{*}{$\begin{array}{c}\text { Stride } \\
\text { velocity }(\mathrm{cm} / \mathrm{s})\end{array}$} & Pre & $73.20 \pm 8.06$ & $51.16 \pm 5.99$ & $71.36 \pm 20.38$ & $48.73 \pm 19.78$ & $113.96 \pm 18.35$ & $102.93 \pm 22.19$ & \multirow{3}{*}{$\mathrm{TG}>\mathrm{CG}$} & \multirow{3}{*}{ ns } \\
\hline & Post & $83.79 \pm 11.45$ & $60.83 \pm 15.95$ & $69.44 \pm 19.52$ & $47.9 \pm 15.19$ & $114.57 \pm 21.92$ & $102.16 \pm 25.09$ & & \\
\hline & Delta & $10.59 \pm 8.89$ & $9.67 \pm 7.75$ & $-1.92 \pm 4.91$ & $-0.83 \pm 8.95$ & $0.61 \pm 9.68$ & $0.77 \pm 13.15$ & & \\
\hline \multirow{3}{*}{$\begin{array}{c}\text { Double } \\
\text { support (\%) }\end{array}$} & Pre & $22.83 \pm 2.85$ & $28.43 \pm 7.15$ & $24.26 \pm 7.86$ & $32.41 \pm 12.69$ & $21.68 \pm 3.75$ & $22.32 \pm 4.49$ & \multirow{3}{*}{ ns } & \multirow{3}{*}{ ns } \\
\hline & Post & $22.19 \pm 3.83$ & $25.84 \pm 5.58$ & $25.68 \pm 7.08$ & $31.61 \pm 10.26$ & $22.01 \pm 5.44$ & $23.06 \pm 6.57$ & & \\
\hline & Delta & $-0.64 \pm 2.84$ & $-2.59 \pm 6.77$ & $1.42 \pm 2.33$ & $-0.80 \pm 4.70$ & $0.33 \pm 2.65$ & $0.74 \pm 2.79$ & & \\
\hline \multirow{3}{*}{$\begin{array}{c}\text { Cadence } \\
\text { (steps } / \text { min) }\end{array}$} & Pre & $98.28 \pm 8.92$ & $72.51 \pm 20.84$ & $101.90 \pm 4.07$ & $72.42 \pm 17.55$ & $108.42 \pm 8.26$ & $98.00 \pm 9.25$ & \multirow{3}{*}{ TG $>$ CG } & \multirow{3}{*}{$\mathrm{ns}$} \\
\hline & Post & $104.04 \pm 10.77$ & $79.53 \pm 18.81$ & $100.84 \pm 3.79$ & $73.12 \pm 13.63$ & $108.46 \pm 10.13$ & $97.01 \pm 11.06$ & & \\
\hline & Delta & $5.76 \pm 5.87$ & $7.02 \pm 7.04$ & $-1.06 \pm 5.75$ & $0.70 \pm 8.51$ & $0.04 \pm 6.24$ & $1.00 \pm 9.99$ & & \\
\hline \multirow{3}{*}{$\begin{array}{c}\text { Counting } \\
\text { errors (errors) }\end{array}$} & Pre & -------- & $1.5 \pm 1.31$ & -------- & $1.64 \pm 1.12$ & -------- & $0.27 \pm 0.47$ & \multirow{3}{*}{ ns } & \multirow{3}{*}{$\mathrm{ns}$} \\
\hline & Post & -------- & $1.75 \pm 1.48$ & -------- & $2.00 \pm 0.77$ & -------- & $0.27 \pm 0.47$ & & \\
\hline & Delta & -------- & $0.25 \pm 1.36$ & -------- & $0.36 \pm 1.28$ & -------- & $0.0 \pm 0.0$ & & \\
\hline
\end{tabular}

TG: Training Group, CG: Control Group; HG: Healthy Group; ns: not significant.

\section{Discussion}

The aims of this study were to identify the effects of aging and $\mathrm{AD}$ on the gait parameters after a four-month period and to investigate the effects of a four-month program of physical activity, with emphasis on cognitive components on gait during single and dual task, in people with AD. The results, in part, fulfilled our expectations. It was expected that the CG would present worsening gait parameters after 4 months, which did not occur. On the other hand, regardless of the type of gait (single or dual task), the individuals with $\mathrm{AD}$ who participated in the exercise program presented increased stride length, stride velocity and cadence, and decreased stride duration, which confirms the importance of this type of non-pharmacological treatment for people with $\mathrm{AD}$. In this way, in the following paragraphs, we provide explanations for the maintenance of the gait parameters of people with $\mathrm{AD}$ who did not participate in the intervention and for the improvements in the gait parameters of people with $\mathrm{AD}$ after a physical activity program with emphasis on cognitive components.

People with AD who did not participate in the intervention showed no significant decline in 4 months. The period used in this study does not seem to be enough for a significant decline in the gait parameters of people with AD. Longitudinal studies have observed the results of disease progression after 1 year ${ }^{22}$ and 2 years $^{23}$. Thus, in future studies, we suggest increasing the period of the physical intervention and/or including a follow-up in the analysis. Notwithstanding, a slight clinical worsening (negative delta) in the gait parameters of the CG and maintenance of the 
HG (delta near zero) were shown in this study. These findings reinforce the importance of carrying out a program of physical activity for people with $\mathrm{AD}$, as over an extended period the worsening of locomotor performance is pronounced in inactive older adults, thus physical activity represents an important nonpharmacological treatment to attenuate the rate of locomotor decline caused by AD.

A program of physical activity with emphasis on the cognitive components was able to improve the mobility of people with AD. Our results show that after training, people with AD presented increased stride length, stride velocity and decreased stride duration. These findings suggest that physical activity can improve the mobility of patients, particularly enhancing balance control in the sagittal plane ${ }^{24-26}$. Hof and collaborators indicated that a stable gait depends on step length, step time and speed ${ }^{25}$. During walking, the center of mass (CoM) moves continuously and its position is confined to a limited area as the base of support ${ }^{24}$. When the CoM displacement exceeds the limit of the base of support, the imbalance becomes evident. Thus, an increase in stride length indicates a larger support base, consequently increasing the area of CoM displacement. An increase in stride velocity and decrease in stride duration are associated with recovery of CoM, in other words, the subject can quickly control the CoM displacement, thus increasing gait stability ${ }^{26}$. In addition, studies have reported that a decrease in stride duration may be a strategy to shorten the unstable phases of the gait cycle (e.g., single leg support times $^{26}$ ). These strategies can be interpreted as greater security and a reduced risk of falls.

The improvement in mobility after an intervention may be explained by various changes in the structure and physiology of the brain, such as increases in brain volume and the hippocampal volume, in brain-derived neurotrophic factor and insulin-like growth factor ${ }^{10}$. In addition, physical activity promotes already known benefits in the functional capacity of people with $\mathrm{AD}^{10}$. In this context, physical activity represents a valuable contribution to the health of neural activity, predominantly related to frontal cognitive functions ${ }^{14,17}$; the settings of the interaction of perceptual, cognitive and motor systems ${ }^{3}$; improved cognitive reserve ${ }^{27,28}$; and physical health during the course of the disease, which can improve metabolic, structural, and functional dimensions of the brain that preserve cognitive and motor performance in older adults, especially gait ${ }^{14}$.

Impairments in cognitive functions can be a major cause of gait disturbances in people with $\mathrm{AD}^{15,22,23}$. However, participation in regular physical activity can reduce cognitive decline and the risk of dementia by increasing cognitive reserve $\mathrm{e}^{27-30}$, which is understood as an extra reserve created from people's lifestyle. Regular exercise expands the cognitive reserve, making the brain able to tolerate changes related to age and pathology, delaying the onset of cognitive decline or the development of dementia ${ }^{27-30}$. Nevertheless, our results demonstrated improvement only in the locomotor component; there was no improvement in cognitive performance (count task). This finding suggests that physical activity with cognitive stimulation results in better reallocation of attention to the walking task, which improves attentional focus on the gait, thus resulting in a safer locomotor pattern ${ }^{31}$.
In addition, there was no difference in double support, which suggests a ceiling effect; in other words, the AD already presented maximum double support duration, and were unable to present further elevation (since a longer double support duration is good for stability). Although the TG presented improved mobility, they still maintained cautious walking patterns, remaining for a longer duration in the double support phase ${ }^{7}$.

The main limitation of this study was the small number of participants. This parameter was unavoidable because of the difficulty of maintaining participants in the program for 4 months. Despite the fact that participation was a generally pleasant experience, family members and caregivers were not always available to bring participants to the program site. Another important limitation was the absence of an active HG. This group would verify that healthy older adults have similar benefits to people with $\mathrm{AD}$ after a program of physical activity with emphasis on cognitive components.

\section{Conclusion}

In conclusion, physical activity with emphasis on cognitive components promotes better reallocation of attention during walking in people with $\mathrm{AD}$, improving attentional focus on the gait and thus resulting in a safer locomotor pattern. The participants with AD in the training group presented improvements in stride length, stride velocity and cadence. The results of this study demonstrate that a physical activity program with cognitive tasks is an important non-pharmacological treatment for people with $\mathrm{AD}$, contributing positively to the mobility of older adults, consequently, reducing the risk of falls. These benefits underscore the importance of including older people, especially those with $\mathrm{AD}$, in physical activity programs.

\section{References}

1. Nadkarni NK, Mawji E, McIlroy WE, Black SE. Spatial and temporal gait parameters in Alzheimer's disease and aging. Gait Posture. 2009; 30(4): 452-454.

2. Della Sala S, Spinnler H, Venneri A. Walking difficulties in patients with Alzheimer's disease might originate from gait apraxia. J Neurol Neurosurg Psychiatry. 2004;75:196-201.

3. Pettersson AF, Olsson E, Wahlund LO. Effect of divided attention on gait in subjects with and without cognitive impairment. $\mathrm{J}$ Geriatr Psychiatry Neurol. 2007;20:58-62.

4. Barbieri FA, Simieli L, Orcioli-Silva D, Vitório R, Stella F, Gobbi LTB. Variability in Obstacle Clearance May (Not) Indicate Cognitive Disorders in Alzheimer Disease. Alzheimer Dis Assoc Disord. 2015; 29:307-311.

5. Simieli L, Barbieri FA, Orcioli-Silva D, Lirani-Silva E, Stella F, Gobbi LTB. Obstacle crossing with dual tasking is a danger for individuals with Alzheimer's disease and for healthy older people. J Alzheimers Dis. 2015; 43: 435-441.

6. Sheridan PL, Solomont J, Kowall N, Hausdorff JM. Influence of executive function on locomotor function: divided attention 
increases gait variability in Alzheimer's disease. J Am Geriatr Soc. 2003; 51: 1633-1637.

7. Orcioli-Silva D, Simieli L, Barbieri FA, Stella F, Gobbi LTB. Adaptive walking in Alzheimer's disease. Int J Alzheimers Dis. 2012; 2012: 1-6.doi:10.1155/2012/674589.

8. Suttanon P, Hill KD, Said CM, Dodd KJ. A Longitudinal Study of Change in Falls Risk and Balance and Mobility in Healthy Older People and People with Alzheimer Disease. Am J Phys Med Rehabil. 2013; 92:676-685.

9. Camicioli R, Licis L. Motor impairment predicts falls in specialized Alzheimer care units. Alzheimer Dis AssocDisord. 2004;18: 214-218.

10. Rolland Y, Abellan van Kan G, Vellas B. Physical activity and Alzheimer's disease: from prevention to therapeutic perspectives. J Am Med Dir Assoc. 2008;9:390-405.

11. Groot C, Hooghiemstra AM, Raijmakers PG, van Berckel BN, Scheltens P, Scherder EJ, et al. The effect of physical activity on cognitive function in patients with dementia: A meta-analysis of randomized control trials. Ageing Res Rev. 2016;25:13-23.

12. Teri L, Gibbons LE, McCurry SM, Logsdon RG, Buchner DM, Barlow WE, et al. Exercise plus behavioral management in patients with Alzheimer disease: A randomized controlled trial. JAMA. 2003;290:2015-22.

13. Santana-Sosa E, Barriopedro MI, López-Mojares LM, Pérez M, Lucia A. Exercise training is beneficial for Alzheimer's patients. Int J Sports Med. 2008; 29: 845-850.

14. Andrade LP, Gobbi LT, Coelho FG, Christofoletti G, Costa JL, Stella F. Benefits of multimodal exercise intervention for postural control and frontal cognitive functions in individuals with Alzheimer's disease: a controlled trial. J Am Geriatr Soc. 2013; 61: 1919-1926.

15. Sheridan PL, Hausdorff JM. The role of higher - level cognitive function in gait: Executive dysfunction contributes to fall risk in Alzheimer's disease. Dement Geriatr Cogn Disord. 2007;24: 125-137.

16. Schwenk M, Zieschang T, Oster P, Hauer K. Dual-task performances can be improved in patients with dementia: a randomized controlled trial. Neurology. 2010; 74: 1961-1968.

17. Coelho FG, Andrade LP, Pedroso RV, Santos-Galduroz RF, Gobbi $\mathrm{S}$, Costa JL, et al. Multimodal exercise intervention improves frontal cognitive functions and gait in Alzheimer's disease: A controlled trial. Geriatr Gerontol Int. 2013;13:198-203.

18. Mortaza N, Abu Osman NA, Mehdikhani N. Are the spatiotemporal parameters of gait capable of distinguishing a faller from a non-faller elderly? Eur J Phys Rehabil Med. 2014;50: 677-391.

19. Folstein MF, Folstein SE, McHugh PR. Mini Mental State. A practical method for grading the cognitive state of patients for the clinician. J Psychiatr Res. 1975;12:189-198.

20. Royall DR, Cordes JA, Polk M. CLOX: an executive clock drawing task. J Neurol Neurosurg Psychiatry. 1998; 64: 588-594.

21. Dubois B, Slachevsky A, Litvan I, Pillon B. The FAB: a Frontal Assessment Battery at bedside. Neurology. 2000; 55: 1621-1626.
22. Wittwer JE, Webster KE, Menz HB. A longitudinal study of measures of walking in people with Alzheimer's Disease. Gait Posture. 2010;32:113-117.

23. Cedervall Y, Halvorsen K, Aberg AC. A longitudinal study of gait function and characteristics of gait disturbance in individuals with Alzheimer's disease. Gait Posture. 2014;39:1022-1027.

24. Hof AL, Gazendam MG, Sinke WE. The condition for dynamic stability. J Biomech. 2005; 38: 1-8.

25. Hof AL, Van Bockel RM, Schoppen T, Postema K. Control of lateral balance in walking. Experimental findings in normal subjects and above-knee amputees. Gait Posture. 2007;25: 250-258.

26. Barbieri FA, dos Santos PC, Simieli L, Orcioli-Silva D, van Dieën $\mathrm{JH}$, Gobbi LTB. Interactions of age and leg muscle fatigue on unobstructed walking and obstacle crossing. Gait Posture. 2014; 39: 985-990.

27. Grande G, Vanacore N, Maggiore L, Cucumo V, Ghiretti $\mathrm{R}$, Galimberti D, et al. Physical activity reduces the risk of dementia in mild cognitive impairment subjects: a cohort study. J Alzheimers Dis. 2014; 39: 833-839.

28. Xu W, Yu JT, Tan MS, Tan L. Cognitive reserve and Alzheimer's disease. Mol Neurobiol. 2015; 51(1): 187-208.

29. Adam S, Bonsang E, Grotz C, Perelman S. Occupational activity and cognitive reserve: implications in terms of prevention of cognitive aging and Alzheimer's disease. Clin Interv Aging. 2013;8:377-90.

30. Fratiglioni L, Wang HX. Brain reserve hypothesis in dementia. J Alzheimers Dis. 2007; 12: 11-22.

31. Yogev-Seligmann G, Hausdorff JM, Giladi N.Do we always prioritize balance when walking? Towards an integrated model of task prioritization. Mov Disord. 2012;27: 765-770.

\section{Acknowledgements:}

The authors thank Stephannie Spiandor Beretta for her assistance with data analysis. Funding sources: This study was supported by the São Paulo Research Foundation (FAPESP) (grant number: \#2011/00414-4).

\section{Corresponding author}

Diego Orcioli-Silva, M.Sc., Universidade Estadual Paulista (Unesp), Instituto de Biociências, Posture and Gait Studies Laboratory (LEPLO), Avenida 24-A, 1515, Bela Vista, 13506-900 - Rio Claro/SP, Brazil.

Email: diego_orcioli@hotmail.com

Manuscript received on May 16, 2017

Manuscript accepted on January 17, 2018

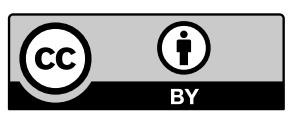

Motriz. The Journal of Physical Education. UNESP. Rio Claro, SP, Brazil - eISSN: 1980-6574 - under a license Creative Commons - Version 4.0 